\title{
Surgery: Down for the count?
}

$\mathrm{S}$ urgery may be in the earliest stages of dissolution as a result of a historic convergence of developments. The discipline as we have known it over the past 150 years may fall victim to technological progress. This is more than a little ironic since surgery has always been dependent on, and benefited from technological innovation. Now, however, we're likely at the tipping point when further innovation will jeopardize the surgeons' traditional role. Whereas in the past, technological breakthroughs often led to an increase in the number, scope and complexity of surgical procedures, the emerging technologies allow for smaller and fewer operations - a trend that will undoubtedly continue as devices become more sophisticated and miniaturized. Moreover, breakthroughs in our understanding of the molecular basis of disease, in imaging and the advent of energy-directed devices will result in dramatic therapeutic advances, some of which are already making certain surgical treatments obsolete.

The rise of modern surgery was characterized by new operative procedures for treating diseases that had previously been treated non-operatively or not at all. ${ }^{1}$ Classic examples are radical mastectomy, which epitomized the notion that cancer could be cured surgically, and treatment of peptic ulcer disease by a potpourri of gastric procedures. These operations are largely of historic interest now.

It is not only the introduction of new technology, but also the change in criteria for effectiveness that has made surgery less attractive. Thus, the analysis of longterm outcomes has played to the disadvantage of some commonly performed surgical procedures, as highlighted by the recent history of coronary bypass surgery. ${ }^{2}$ In a prominent Businessweek exposé, ${ }^{3}$ leading American cardiologists voiced the opinion that except in a minority of patients with severe disease, bypass surgery does not prolong life or prevent future heart attacks and that consideration should be given to retiring the procedure in the face of equally effica-

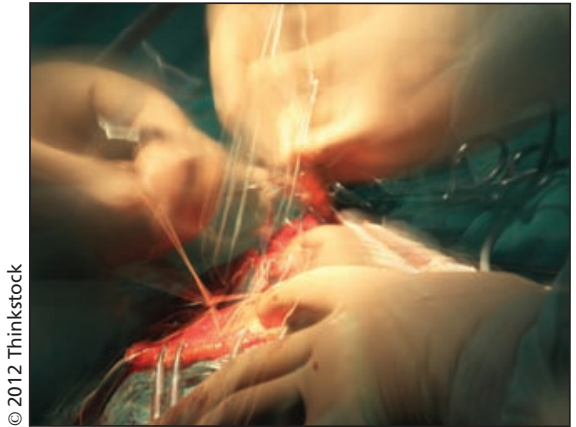

cious pharmacologic alternatives with or without stenting procedures performed by nonsurgeons.

By the 1970s, the steady increase in operative rates levelled off. In the early 1980 s, the number of operations performed per surgeon actually decreased by 25 per cent. ${ }^{4}$ This decrease went along with a change in the spectrum of surgical interventions, many of which were challenged and sometimes replaced by pharmacologic, radiologic, and endoscopic treatments or by watchful waiting. Surgeons were thereby effectively removed from the medical team evaluating and diagnosing patients, to holding a downstream position in health care delivery. ${ }^{4}$

Furthermore, advanced imaging now extends beyond diagnosis into the interventional realm too. The trend will be away from mechanical instruments, to energy-directed instruments, including high-intensity focused ultrasound, thermal-directed systems, microwave instruments and femtosecond lasers. ${ }^{5}$

The replacement of traditional surgery by new technologies is an example of disruptive innovation, ${ }^{6}$ a concept that explains how otherwise wellmanaged enterprises and professions fail to deal with the advent of disruptive technologies. This failure doesn't stem from a lack of access or understanding of the technology itself, but from an organization's structure and practices that preclude it from recognizing and adopting the disruptive technology until it is too late to compete. ${ }^{6}$

Since these technologies don't have the traditional surgical profile, there are ongoing controversies about who should take charge of them. For example, vascular surgeons and interventional cardiologists and radiologists can all claim expertise in managing thoracic aneurysms by endovascular technologies. Eventually, the vascular interventionalist may not even need to be a physician. A skilled interventionalist primarily requires computer-gaming skills that a nonphysician could acquire through practice.

It is now clear that during the waning years of the 20th and the early 21st century, the impact of technological change on the surgical profession is fundamentally different from earlier periods. Thomas J. Russell, former executive director of the American College of Surgeons, is right in saying that "the practice of surgery just isn't what it used to be." The "meaning of surgery has changed, driven by advances in technology." The traditional dichotomy of surgical and nonsurgical treatment, and between what surgeons do and what nonsurgeons do, is becoming a blurred boundary increasingly without substance.

As these developments unfold, surgeons will have to reinvent themselves in a manner that will undoubtedly influence the professional identity of its practitioners; and surgery as an occupational discipline, could well disintegrate. Although this can be seen as a chance for necessary adjustments, it also entails risks, such as the widespread loss of general surgical skill to the disadvantage of patients in need of such surgical competency. Therefore, today's surgeons need to participate actively in the shaping of the emerging health care delivery frontier in which they will still have a stake.

\section{Lawrence Rosenberg PhD MD \\ Department of Surgery \\ Thomas Schlich MD Dr habil \\ Social Studies of Medicine \\ McGill University \\ Montréal, Que.}

For references, see Appendix 1, available at www.cmaj.ca/lookup/suppl/doi:10.1503 /cmaj.112180/-/DC1

CMAJ 2012. DOI:10.1503/cmaj.112180 